Boise State University

ScholarWorks

9-30-2013

\title{
A Categorical Data Analysis on Relationships Between Culture, Creativity and Business Stage: The Case of Vietnam
}

Quan Hoang Vuong

Universite Libre de Bruxelles

Nancy K. Napier

Boise State University

Tri Dung Tran

DHVP Research and Consultancy 


\title{
A Categorical Data Analysis on Relationships Between Culture, Creativity and Business Stage: The Case of Vietnam
}

\author{
Quan Hoang Vuong* \\ Centre Emile Berheim \\ Universite Libre de Bruxelles \\ Brussels, Belgium \\ qvuong@ulb.ac.be \\ *Corresponding author \\ Nancy K. Napier \\ Boise State University \\ Boise, Idaho \\ nnapier@boisestate.edu \\ Tri Dung Tran \\ DHVP Research and Consultancy \\ Hanoi, Vietnam \\ tran@vietnamica.net
}

\begin{abstract}
In this paper, we offer a new way of exploring relationships between three different dimensions of a business operation, namely the stages of business development, the methods of creativity and the major cultural values. Although separately each of these has gained enormous attention from the management research community, evidenced by a large volume of research studies, few studies have attempted to describe the logic that connect these three important aspects of a business, let alone develop empirical evidence that supports any significant relationships among these variables. This paper also provides a dataset and an empirical investigation on that dataset, using a categorical data analysis, to conclude that examinations of these possible relationships are meaningful, even for seemingly unquantifiable information. The results also show that the most significant category among all creativity methods employed in Vietnamese enterprises is the idea of 'creative disciplines' in the 'entrepreneurial phase'.
\end{abstract}

Keywords: 3D creativity; serendipity; Aha! Moment; cultural values; entrepreneurship; categorical data; log-linear model; Vietnam.

\section{Introduction}

For decades, thanks to studies by scholars in many research disciplines, culture has become an accepted factor that relates to the organisational process of setting values, building goals and guiding behaviours of employers and employees. Researchers have also examined other factors, such as business stage of development (e.g., start-up or entrepreneurial versus established mature firms), which plays a role in organisational success, in particular, in contribution to wealth creation in society but also by investing in new methods, new products help shape part of the changing cultures, and reinforce and realise true values of creativity.

Could these two factors, then, when joined by a third - creativity - may make organisations even more likely to succeed? In recent years, creativity has come under increasing scrutiny as a resource, renewable and 'unrestrictable', in that it resides in no specific person, place or organisation. Rather than complementing only the concept of 'optimising currently available resources' to obtain the best output/value possible for owners and stakeholders of the business firm or sector, creativity may rather yield the capability of making substantial changes either in the technology that firms use to manufacture better consumer goods, or of inventing new business logics and models 
This is an author-produced, peer-reviewed version of this article. The final, definitive version of this document can be found online at International Journal of Transitions and Innovation Systems, published by Inderscience. Copyright restrictions may apply. doi: 10.1504/IJTIS.2013.056595

that help to create new service markets, or of generating new methods that could turn waste of time and/or energy into new kind of value. In today's global market, then, creativity may become key to building cutting edge competitive advantage and building corporate financial value.

In this paper, we explore insights from these three management issues - culture, growth stage and creativity - to examine relationships among them and to present a tentative assessment of what those links might be and how they play out. We first review selected relevant literature related to the three key factors, namely relevant creativity dimensions, cultural values and stages of business development. Following the review, we explore how to examine the factors, in particular a method and exploratory data to carry this out. We then discuss the findings from this initial examination and possible implications and future research directions.

We use Vietnam as the research context for several reasons. First, it is a prime example of a fast changing emerging economy, with GDP growth averaging $7.22 \%$ in the last decade. Second, despite of the dominance of state-own enterprises, small and medium scale enterprises (SMEs) are widely considered the driving force of Vietnam's economic growth (Vuong and Tran, 2009), especially since the financial turbulence that started in 2008. The expectation is that the SMEs' capacity of creating new services and products - and of course, new jobs - could help the country get out of economy stagnation and is more likely than from the state owned enterprises. Finally, the concepts relating to creativity have not received as much attention yet in Vietnam, so using it as an example may yield some new insights not seen in more developed settings.

\section{Brief Review of Selected Literature}

In this section, we will review briefly literature relating to the three broad variables or factors we will examine:

- 1 creativity/insight/serendipity

. 2 organisational growth stage

. 3 culture.

\section{$\underline{2.1 \text { Creativity, insight and serendipity }}$}

Creativity can be considered a broad 'umbrella' term comprising several concepts, including insight and serendipity. All three have been researched for their relationships to individuals; more recently, some researchers have begun to consider whether the concepts could also be developed at an organisational level, eventually as a way to build competitive advantage. We review briefly the three concepts below.

\subsubsection{Creativity}

As we mentioned, research on creativity has long tended to focus on individuals (e.g., John-Steiner, 1997; Runco and Richards, 1997; Runco, 2004; Sternberg, 1999). Klein (1982), for example, conducted a survey on words and phrases that people - ranging from novelists and musicians, to social scientists and high school students - use to define creativity. The result was a diverse set of words and phrases, demonstrating that creativity is a catch all term. Some characteristics and behaviours were similar across groups, however, including the following:

- 1 Ability to maximise options and broaden perceptions of behavioural alternatives.

. 2 Ability to defer judgement, accept all ideas as plausible and eliminate prejudice on all levels.

. 3 Being inconsistent, or “... more primitive and more cultured, more destructive and more constructive, and crazier and saner than are average people” (Barron, 1963).

. 4 Ability to seek freedom from conventions and habits.

- 5 Being action oriented with a focus on not just thinking of good ideas but acting on them.

. 6 Being aware of inner and outer worlds, in terms of where people are, whether they want to be there, where they do want to be, and how they are going to get there.

. 7 Being responsible/responsive to his/her needs and to the world.

- 8 Having a positive orientation that increases self-concept and confidence.

- 9 Willing to take risks: risk avoiding can result in a lack of growth, limited horizons, and a boring daily life.

Klein offers a three-dimension model for identifying factors comprising individual creative behaviour (Figure 1), 
This is an author-produced, peer-reviewed version of this article. The final, definitive version of this document can be found online at International Journal of Transitions and Innovation Systems, published by Inderscience. Copyright restrictions may apply. doi: 10.1504/IJTIS.2013.056595

including modes of behaviour (e.g., cognitive) , contents of behaviour (e.g., ability to perceive), and processes of behaviour (e.g., flexibility and elaboration).

Figure 1 Klein's model of creative behavior

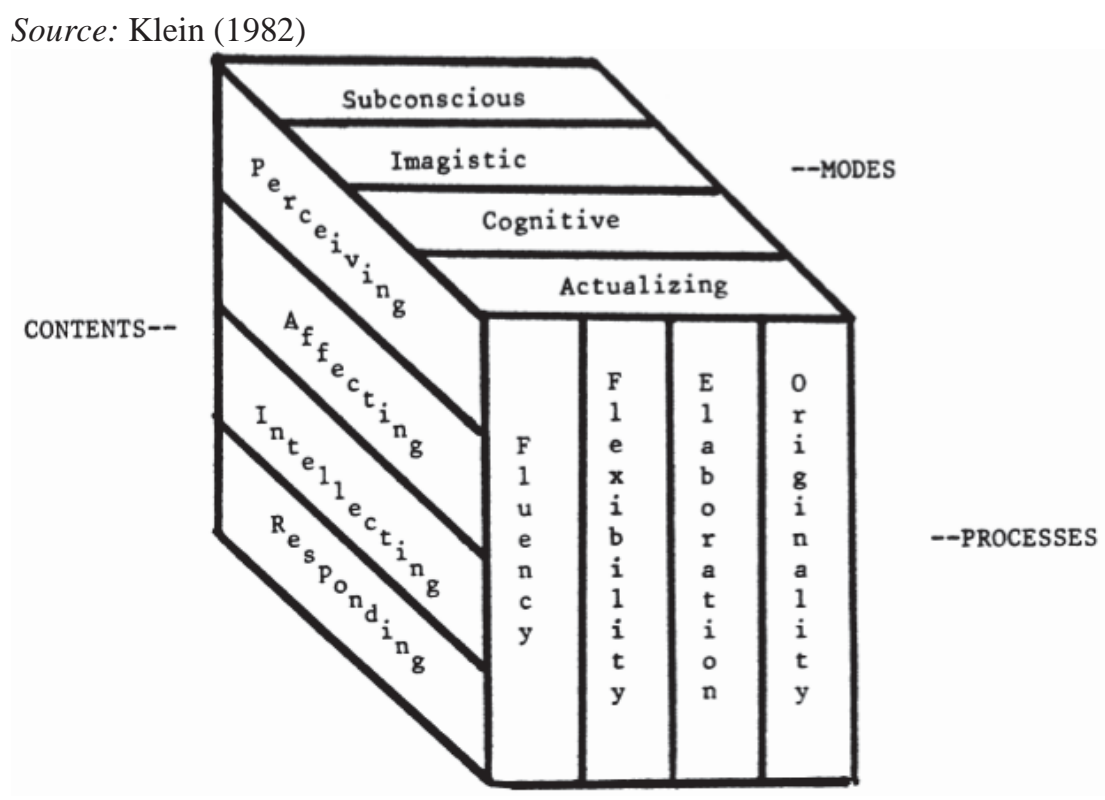

Glaveanu (2010) defines creativity as capacity to bring about the new, especially the creative product, which is new, useful, appropriate or meaningful. He argues that creative expression is a form of cultural expression and, ultimately, one of the most illustrative forms of cultural participation. He uses Yin and Yang symbols to describe the interdependence of culture and creativity: "Culture is not only a resource but also a directing force". Therefore, "the 'richer' the contact with cultural elements, the more remarkable the creations". On the other hand, creativity is "the main engine behind cultural change and transformation.”

Similar to others, Kronfeldner (2009) uses novelty (i.e., original, unexpected) and appropriateness (i.e., useful, adaptive concerning task constraints) in defining creativity. For her, novelty leads to originality and spontaneity. The former explains why something must be novel in order to be a product of creativity. The latter answers why 'unexpected' and 'surprising' are needed. Further, Kronfeldner defines originality as a specific double causal independence-learning from others and learning from individual experience. "A potter is creative only if he does not copy the activities of others or an original pot [even the pot was made by himself]." However, "training in pottery does not make it the case that a trained potter cannot be creative." The knowledge which the potter accumulated over the years [from others and himself] is necessary for him to be able to come up with the [new] idea as well as allows him to judge it appropriate.

Originality is not the only essential characteristic of creativity. When learning and experience diminish originality, there will still be spontaneity. Kronfeldner argues that creativity comes in degrees. Although a child obtains a lot of information from his teacher, as long as the teacher is not presenting the solution 
This is an author-produced, peer-reviewed version of this article. The final, definitive version of this document can be found online at International Journal of Transitions and Innovation Systems, published by Inderscience. Copyright restrictions may apply. doi: 10.1504/IJTIS.2013.056595

directly, "the child has to be creative to some degree." The teacher defines the problems and gives the child almost everything he needs but the teacher withholds the answer. "Creativity does not react to orders. It occurs spontaneously, if it occurs at all.”

While many researchers still focus on creativity at the individual level, in the last two decades some focus has moved toward how organisations can develop and use it (Amabile, 1996; Amabile and Conti, 1999; Degraff and Lawrence, 2002; Napier and Nilsson, 2008; Paulus and Nijstad, 2003; Unsworth, 2001). Creativity increasingly has been considered a resource, potentially useful even beyond organisational competitiveness to include countries (Napier et al., 2006) and communities as well (Florida, 2002, 2005; Kao, 2007).

With regard to organisations, in particular, elements of creativity include a disciplined process and a culture that enhances it. Napier and Nilsson (2008) describe three disciplines (i.e., 3D creativity) as critical for implementation of creativity. They include 'out of discipline' thinking, 'within discipline' expertise, and a 'disciplined process'. First, out of discipline thinking involves looking beyond a discipline or field for ideas. Out of discipline thinkers absorb information from sources beyond their normal boundaries and fields and then seek to understand how the ideas might apply in their situation. Second, within discipline expertise focuses on how individuals become the best in their fields and then, with that fundamental expertise base, move onto thinking more creatively. The notion is that when the best in a field work (or compete) together, they can learn and improve faster from each other, allowing them to come up with new ideas in the process. Third, a disciplined process means that organisations use routine and structure to allow more creativity.

\subsubsection{Insight or aha moments}

Insight or 'aha moments' is typically defined as the sudden awareness of a problem solution or understanding of some idea (e.g., learning a language, realising a life lesson). The process, which can be mapped, generally consists of several stages (Napier, 2010; Wallas, 1926). First, an individual (or in the case of a group moving toward a 'collective aha moment') gathers or receives overwhelming amounts of information on the topic of interest or problem to be solved. This 'sort stage' beings, then, with a sense of too much dispersed and unconnected information, and then moves into a period which involves chunking and sorting the information into understandable categories. At this point, an insight - 'connecting the dots' - may occur but if it does not, the next phase should begin. During the 'spark stage', individuals and groups can use several techniques to generate the sudden awareness or understanding. Such techniques include, for example, looking at a problem 'in reverse', or from an unusual angle, bringing together ideas from very different domains, and allowing for 'simmering' or some time to pass when the 'unseen mind' works subconsciously on the problem. Once insight occurs, a final 'checking stage' to verify the result is critical to be sure that the aha moment lesson can be generalised beyond a single incident.

\subsubsection{Serendipity}

Finally, the concept of serendipity is similar to insight in that it typically involves integrating sometimes diverse ideas but there are distinct differences. Typical characteristics that emerge in the definition of serendipity are:

. 1 unsought, unexpected, unintentional, unanticipated event or information

. 2 something out of the ordinary, surprising, anomalous, inconsistent with existing thought, findings or theory

- 3 an alertness or capability to notice what others do not, to recognise, to consider, and to connect previously disparate or discreet pieces of information to solve a problem or find an opportunity.

Napier and Vuong (2012) reviewed literature on serendipity and its importance, conditions, the making process and raised the question of whether it could be developed as an ability to recognise and leverage unexpected information to create value from it. Their definition of serendipity is an ability (that can be developed) to notice, evaluate, and take advantage of unexpected information better or faster than competitors. An important distinction is that information appears unexpectedly and only within the context of a problem or opportunity does it come together to create something of value. Further, the ability to notice the information is also a key. Unexpected information appears regularly at the doorstep of individuals and organisations, but if it goes unnoticed, it never has the chance to be leveraged. Thus, the ability to notice, the ability to evaluate, and the ability to turn that information into something of value are key to the process. 
This is an author-produced, peer-reviewed version of this article. The final, definitive version of this document can be found online at International Journal of Transitions and Innovation Systems, published by Inderscience. Copyright restrictions may apply. doi: 10.1504/IJTIS.2013.056595

\subsection{Organisational growth stage}

Greiner (1994) divides organisation development into five stages. The first stage, interestingly, is named 'creativity'. The next four are 'direction,' 'delegation,' 'coordination,' and 'collaboration'. At the beginning of a start-up company, technically and entrepreneurially oriented founders focus on creating new products and/or new markets. This is likely to result in a casual management style where the founders/managers, and the company's staff members communicate frequently and informally. Company members are often offered a profit sharing scheme, such as stock options, as an additional compensation. In other words, the difference between the founder/managers and the employees is minor. Key staff, such as a proficient sales people or engineers, is critical to the growth of the company, sometimes almost more than the owners. We have observed such relations in family-run firms in Vietnam, for example. Thus, in this article, we define the first stage of development an 'entrepreneurial phase.'

As the business expands and becomes more established, a hierarchy organisation may emerge, generating bigger differences between the owners, the managers, the mid-managers, and other staff members. The owners are now more likely capitalists using financial resources and social capital (i.e., personal reputation and relations) to direct the company. Our research objectives include not only business owners but also professional top managers who direct the businesses not purely based on their entrepreneurial spirits.

\subsection{Dimensions of national culture}

Hofstede, in his oft cited classic Culture's Consequences (1984), used an existing data bank from IBM, to examine matched populations of employees in national subsidiaries in 64 countries. From the data, he introduced four dimensions of national cultures:

. 1 individualism vs. collectivism

. 2 masculinity vs. femininity

. 3 power distance

. 4 uncertainty avoidance.

Following the results of the survey conducted by Michael Harris Bond and colleagues in 1991 (http://www.geerthofstede.nl/culture/dimensions-of-national-cultures.aspx), Hofstede added a fifth dimension to his model, long-term vs. short-term orientation, which was initially called Confucian dynamism. Hofstede's sixth dimension - indulgence versus restraint - resulted from Minkov's (2007) interpretation of World Values Survey. For the discussion in this paper, we use Hofstede's six dimensions of national culture.

In a collectivist setting like Vietnam, widening a relationship base, which assumes a long-term orientation, may be one of the most important methods of building business competency and advantage, rather than professionalism, quality improvement, and product innovation. Napier and Thomas (2004) note that careful relation management is crucial to business success for foreign managers in transition economies. In addition, when less powerful members of society accept and expect inequality, they have little motivation to change their position in the value chain. In other words, they are reluctant to either improve useful solutions or create new products. Thus, for Vietnamese business people and entrepreneurs, short-term orientation and uncertainty avoidance may be common and can prevent them from pursuing large value-creation endeavours (Kolh, 2007) and greatly affects the business interactions among Vietnamese and with foreigners. In addition, Vietnamese business people simply pursue business dealings in ways that may seem baffling to foreigners, Napier and Vuong (2011) provide foreign businesspeople with examples of some of those challenging ideas, such as understanding the notion of who does what during dealings, the use of 'seed capital', the concept of 'disguised entrepreneurs', different perspectives on human resource management, and the role of strategic partners. The authors also suggest the use of culture interpreters that is professional consultants/consulting firms - to eliminate the cultural gaps and avoid misunderstanding.

\section{Exploratory Research Questions}

The literature review raises questions of what may affect selected aspects of human resource management within organisations. Specifically, we consider cross-cultural aspects and the capability to create business solutions or products over different stages of business development and offer three exploratory research questions as for this investigation: 
This is an author-produced, peer-reviewed version of this article. The final, definitive version of this document can be found online at International Journal of Transitions and Innovation Systems, published by Inderscience. Copyright restrictions may apply. doi: 10.1504/IJTIS.2013.056595

. a What are the key elements in the relationships among cultures, creativity types and stages of corporate growth?

. b What methodology is useful to examine empirically those hypothetical relationships among the variables?

. c. What can we learn from the empirical data and the validity of the insights and implications, for both research and business?

We address the first two questions in the methodology and its subsections and the last one in the conclusion and implications section.

\section{Methods of Investigation}

First, we draw upon research from several sources to generate propositions on various types of creativity (e.g., Napier and Thomas, 2004; Napier and Nilsson, 2008; Napier and Vuong, 2012). Drawing on such work, we selected three major types of creativity:

. 1 creative disciplines

. 2 aha-moments

. 3 serendipity.

They are nominally distinctive values of a variable called 'creativity' in our model. Second, we wanted to examine cultural dimensions in relation to creativity and chose to examine three properties that capture our data sample, discussed in the next subsection. We refer to those dimensions as 3Rs:

. 1 relationship-based value

. 2 high risk tolerance

- 3 high reliance on resources.

And lastly, we chose to examine two major - and conceptually distinctive - stages of business development:

. 1 entrepreneurship

. 2 mature, well established business stages.

These eight different factors could help describe possible interactions between management issues of creativity, culture and period of development, which could also be regarded as three categorical variables.

While the theoretical appreciation could be straightforward, specific locality and time may prohibit us from empirically verifying a hypothetical proposition. Thus, the problem for three categorical variables, as we mentioned above, would be most likely a non-trivial one, even if a few or many of hypothetical relationships later turn out to be unsupported by empirical evidence. Logically speaking, for a specific dataset, in our case drawn upon a group of Vietnamese businesses, a rejected hypothesis on a likely relationship will not automatically damage the model of interactions between the elements, but likely shows a possibility of variations in different samples over time, places and settings.

In terms of an empirical strategy for examining these theoretical arguments about relationships among creativity types, 3R and stages or between pairs of any two of them, we decided to use statistical methods that deal with categorical data. Also, given the three variables described above, our model of three-way dataset is adequate to reflect parsimonious relationships while not quite obvious to confirm any of these. Technical details of such a categorical data analysis - suitable for our task of considering this management problem - are offered in Agresti (2002), and Azen and Walker (2011). Details on estimation and inferences are provided in Stokes et al. (2000).

The essence of our empirical verification of relationships among the variables is to setup a relevant dataset and subsets, then to seek evidence of independence vs. associations among variables, and covariate - when three-way joint frequency tables are applicable - and then to examine statistical (in)significance of key factors present in our model. To look deeper into the issues of magnitude of influences among elements, or groups of elements, in the model, we used a log-linear model to provide more insights. Consequently, estimating parameters, constructing confidence intervals and confirming the meaning of factors in the model at the desired level of statistical 
This is an author-produced, peer-reviewed version of this article. The final, definitive version of this document can be found online at International Journal of Transitions and Innovation Systems, published by Inderscience. Copyright restrictions may apply. doi: 10.1504/IJTIS.2013.056595

significance are at the heart of the performance test.

Although details for technical aspects of methods employed are beyond the scope of this paper, and in fact is a whole realm of statistics theory in itself, a brief description of how these methods follows.

\subsection{Analysis of association vs. independence using contingency tables}

Contingency tables are comprised of count data - such as in Table 2 - appearing as the so-called joint frequency, denoted as $n_{i j}$ in a two-way table (e.g., $n_{12}=18$ in Table 5), or $n_{i j k}$ in three-way tables (n221 = 28 in Table 3). The value appears in a cell in the margins of the table is marginal frequency, which is a row/column total for one category of one variable. For each $2 \times 2$ table, row (column) total is noted $n_{i^{+}}\left(n_{+j}\right)$. Observed marginal probabilities are therefore $\mathrm{pi}^{+}=\left(\mathrm{n}_{\mathrm{i}^{+}} / \mathrm{n}_{++}\right)$for rows, and likewise for column. Total number of observations is therefore denoted as $n_{++}$. Tables 3 and 5 appear in the next section, where we discuss the dataset.

Independence (association) between categorical variables, using contingency tables of count data, is evaluated using odds ratio, with a key principle that if independence holds then true joint probability of a cell in the population satisfies:

$\pi \mathrm{ij}=\pi \mathrm{i}+\pi+\mathrm{j}$, which leads to the use of odds and estimated odds ratio for $2 \times 2$ table as follows:

$\mathrm{Odds}=\pi /(1-\pi)$

Oddsratio $(\theta)=(p 11 / p 12)(p 21 / p 22)=(n 11 n 22)(n 21 n 22)$

Inference for odds ratio is performed through the use of $\log$ odds ratio $\ln (\theta)$ and the constructing of confidence interval around the estimated $\log$ odds ratio, determined by: $\ln (\theta) \pm z_{\alpha / 2}$ s.e.; where standard error (s.e.) of the $\log$ odds ratio is computed by:

s.e. $=[(1 / n)+(1 / n)+(1 / n)+(1 / n)],\lfloor 11122122\rfloor$

and $\mathrm{z}$ follows a standard normal distribution; $\alpha$ is the power of the test for determining the confidence interval of (1$\alpha$ ), usually $95 \%$.

Our dataset was then examined for expected frequencies under the null hypothesis of statistical independence $\left(\mathrm{H}_{0}\right)$. The most common test statistic used is the likelihood ratio one, defined as:

$\mathrm{G}^{2}=2 \sum_{\mathrm{I}} \sum_{\mathrm{J}} \mathrm{O}_{\mathrm{ij}} \ln \left(\mathrm{O}_{\mathrm{ij}} / \mathrm{E}_{\mathrm{ij}}\right)$

Which is chi-square statistic at (I-1)(J-1) degrees of freedom. Other related test statistics included Cochran-MantelHaenszel $(\mathrm{CMH})$ and Breslow-Day for three-way contingency tables. These are also $\chi^{2}$ variables and both are evaluated to test against $\mathrm{H}_{0}$ of statistical independence. Agresti (2002), and Azen and Walker (2011) provide accessible discussions on validity, technical details and applications of these.

\subsection{Models employed in this examination}

Our examinations take advantage of resulting relationships between natural log taking $\ln ($ lambda) of predicted outcome and level of the predictors, in a linear relationship:

$g(E(Y))=\ln (E(Y))=\ln (\lambda)=\alpha+\beta(X)$

normally called the log link function, which constitutes the Poisson regression model, a specific type of the generalised linear model (GLM) and is evaluated using maximum likelihood estimate (MLE).

We used the following equations to assess independence vs. association among categorical variables and between 
This is an author-produced, peer-reviewed version of this article. The final, definitive version of this document can be found online at International Journal of Transitions and Innovation Systems, published by Inderscience. Copyright restrictions may apply. doi: 10.1504/IJTIS.2013.056595

certain pairs of them. Equation (1) is referred to as homogeneous association specification and is used to verify the need of a three-way

\section{$/ / \sqrt{ }$}

interaction term in an estimation model (i.e., the saturated model). Equations (1) to (4) are conditional associations, and the last one is for fitting to a statistical independence model.

$\log (\mu)=\lambda+\lambda \mathrm{X}_{+\lambda} \mathrm{Y}+\lambda^{\mathrm{Z}}$ ijk ijk

$\log (\mu)=\lambda+\lambda \mathrm{X}_{+\lambda} \mathrm{Y}+\lambda^{\mathrm{Z}}$ ijk ijk

$\log (\mu)=\lambda+\lambda X_{+\lambda} Y_{+\lambda} Z_{i j k ~ i j k}$

$\log (\mu)=\lambda+\lambda X+\lambda{ }^{Y}+\lambda^{Z}$ ijk ijk

$\log (\mu)=\lambda+\lambda \mathrm{X}+\lambda \mathrm{Y}+\lambda^{\mathrm{Z}}$ ijk i j k

${ }_{+} \mathrm{XY}+{ }_{+\lambda} \mathrm{XZ}+\lambda \mathrm{YZ}$ (1) ij ik jk

$+{ }_{+\lambda} X Y+\lambda X Z(2)$ ij ik

${ }_{+\lambda} \mathrm{XY}+\lambda \mathrm{YZ}(3) \mathrm{ij} \mathrm{jk}$

$+\lambda \mathrm{XZ}_{+\lambda} \mathrm{YZ}_{\text {(4) } \mathrm{ij} \mathrm{jk}}$

(5)

Coefficient $\lambda$ 's from these fittings need to be exponentiated for interpretation. When performing tests, related statistics - such as Wald and p-value - are reported to gauge each parameter's significance. Following these estimations, we need the log likelihood ratio $\mathrm{G}^{2}$ chi-square statistic 'deviance change', defined as:

$\mathrm{G}^{2}=2 \sum_{\sum} \mathrm{Oln}(\mathrm{O} / \mathrm{E})$,

where the sum is over all cells, O observed and E expected values; and the null hypothesis H0 states that the observed data fit the model, for selecting the best fitted model to explain our dataset. Conventional levels of significance of 1, 5 and 10\% are employed for evaluating estimated parameters. 
This is an author-produced, peer-reviewed version of this article. The final, definitive version of this document can be found online at International Journal of Transitions and Innovation Systems, published by Inderscience. Copyright restrictions may apply. doi: 10.1504/IJTIS.2013.056595

\section{$\underline{4.3 \text { Data }}$}

One of the key issues, especially in Vietnam's transition economy, is quality of the dataset(s) used in any work. The early treatment of original data, which helps transform them into a dataset useful and ready for a test performance, represents a critical work in our actual undertaking of this study. This section, then, reviews our dataset.

The data includes 115 count data entries: $60 \%$ were collected from secondary sources, mainly journalistic articles or local Vietnamese media. The remaining 40\% came from observations and experiences of the two Vietnamese researchers through their work with entrepreneurs and businesspeople over a long period of time, in many cases up to 15 years. Every data entry has one corresponding individual record. The record consists of original information, as illustrated in Table 1.

Our observations are success stories of entrepreneurial and mature businesses to the extent that the businesses are performing well and the business owners/managers reach some well-known, above-average achievements when the stories are reported.

In defining a person as an entrepreneur or businessperson, we considered what he/she appears to be at the current stage of his/her career. In some records, the original information provided stories about people at the beginnings of their business life as journalists often take snapshots of the entrepreneurial process. In other words, the stories describe them as entrepreneurs. However, we observe the whole progress of careers and define those people businessperson because they are now running well-established enterprises whose brand and reputation are widely recognised.

An assumption is that when people face great difficulties, they are forced to be creative or their organisations will decline or die. In transition economies, we might expect that creativity would occur under conditions of economic shock, or 'big bang' economic reform, which was common in some of the Eastern European states like Russia and Poland, but is not the case in Vietnam. Vuong et al. (2011) argue that despite economic difficulties in late 1970s and 1980s, Vietnam's reform policies have been created and implemented gradually as a result of the leaders' entrepreneurial process. Thus, 'Vietnamese creativity' emerged during a ten-year (1976-1986) of a disciplined process of implementing out-of-the-box thinking by entrepreneurial leaders. 
This is an author-produced, peer-reviewed version of this article. The final, definitive version of this document can be found online at International Journal of Transitions and Innovation Systems, published by Inderscience. Copyright restrictions may apply. doi: 10.1504/IJTIS.2013.056595

\section{Table 1}

Individual record

Id Name Company Industry Year of business Attributes

$:::::$

The Id is a unique code of an observation. Name of the person Name of institution (if any) Field of business

Number of years in doing the business of the person

[Stage of business development (qualitative assessment)] Start-up, household/family business, uncertainty of future growth Well established, sustainable growth, widely recognised brand

[Select only one type of creativity] A process of creating value resulted from 3D creativity A solution that comes suddenly after 'working' on it for some time Application of unexpected information - an unexpected outcome

[Select only one cultural values] Reliance on personal relations to conduct business Tendency of the businessman to take higher risks Availability of resource or ability to mobilise resource

- Entrepreneur

- Businessperson

- Creativity

- Aha

- Serendipity

- Relationship

- Risk tolerance

- Resources Source:

$:$ :

$:::$

$:::$

[Select only one]

There are stories/articles about the person. Original information and data can be in either English or Vietnamese. 
This is an author-produced, peer-reviewed version of this article. The final, definitive version of this document can be found online at International Journal of Transitions and Innovation Systems, published by Inderscience. Copyright restrictions may apply. doi: 10.1504/IJTIS.2013.056595

Figure 2 Gathering individual records into datasheet and constructing $3 \times 3 \times \mathrm{K}$ tables (see online version for colours)

We gather individual records into an Excel sheet to build a complete dataset and construct the $3 \times 3 \times \mathrm{K}$ tables, illustrated in Figure 2. Each individual record has a unique

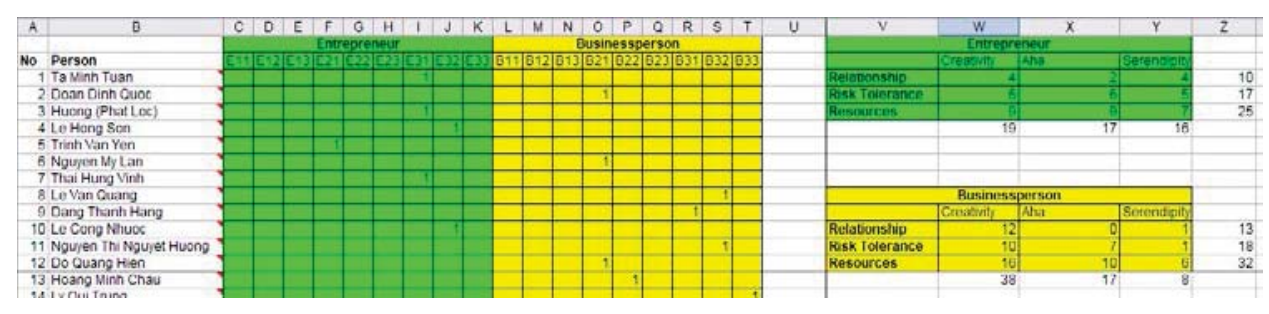

entry in a row. Aggregates of column are presented in corresponding cells of 'entrepreneur (E)' and 'businessperson (B)’ tables.

Take the first entry as an example. He is an entrepreneur. His business is a creativity of new healthcare service. And to get his business up and running, the entrepreneur successfully raised funds of approximately US $\$ 800,000$. We therefore put value ' 1 ' in the first row, E31 column. In the right-hand 'entrepreneur' table, the cell of 'resources' row and ‘creativity’ column presents a sum of E31 column.

The constructing of our major dataset is presented in Table 2. Frequent and random checks on quality of data entries ensure the appropriateness and relevance to related theories in creativity, entrepreneurship and business culture. ${ }^{1}$ Table 2 indicates that the 'stages of business development' variable is a covariate, with two different values of $\mathrm{E}$ (entrepreneurship) and B (well-established business) at each, two $3 \times 3$ partial tables are constructed with 52 and 63 count data points, respectively.

Table 2 The $3 \times 3 \times \mathrm{K}$ data structure with $\mathrm{K}=2$ representing the covariate of stage of business development

\section{Cultural value}

Cultural value

Entrepreneur (E) Type of creativity

$3 D$ creativity Aha! Serendipity

Relationship 42410 Risk tolerance 66517 Resources 99725

19171652

Businessperson (B) Type of creativity

3D creativity Aha! Serendipity

Relationship 120113 Risk tolerance 107118 Resources 1610632 3817863 
This is an author-produced, peer-reviewed version of this article. The final, definitive version of this document can be found online at International Journal of Transitions and Innovation Systems, published by Inderscience. Copyright restrictions may apply. doi: 10.1504/IJTIS.2013.056595

For another way to look at the issue of relationships, we observed the rule of being 'simpler' and reduced the three types of creativity into three values of the creativity dimension of our model space. Also, we considered 'relationship' as part of 'resources' in general, since it is true in many Asian economies (Napier and Thomas, 2004; Vuong and Tran, 2009), especially in those East Asian Confucianism system. The result was a dataset used of $2 \times 2$ $\times \mathrm{K}$, with $\mathrm{K}=3$, and shown in Table 3 .

As we analysed the data, we shifted from $3 \times 3$ tables to $2 \times 2$, showing the development of logic over time. Vuong and Tran (2009), and Vuong et al. (2010) explain how business owners mobilise resources by exploiting relations in Vietnam. For instance, the more people business owners have relations with, the more trust they gain from the others and the easier it is for them to sell equity and ask for loans. In addition, in a transition economy, since many resources are controlled by the state, having relations with the government and the bureaucrats provide both public and private enterprises with competitive advantages.

For Tables 2 and 3, it was straightforward to produce two corresponding two-way datasets by ignoring the covariates, presented in Table $4(3 \times 3)$ and Table $5(2 \times 2)$. Additional analysis compared these with results from the three-way table examinations, which we discuss in the final section. In Table 5, we did separate entrepreneur from businessperson.

Table 3 The $2 \times 2 \times \mathrm{K}$ data structure with $\mathrm{K}=3$ representing the covariate of sources for creativity

Cultural value

Cultural value

Cultural value

$3 D$ creativity Stage of development

$E B$

Risk tolerance 61016 Resources 132841193857

Aha! Moment Stage of development

$E B$

Risk tolerance 6713 Resources 111021171734

Risk tolerance Resources

Serendipity Stage of development

$E B$

5161171816824 
This is an author-produced, peer-reviewed version of this article. The final, definitive version of this document can be found online at International Journal of Transitions and Innovation Systems, published by Inderscience. Copyright restrictions may apply. doi: 10.1504/IJTIS.2013.056595

Table 4 The $3 \times 3$ structure between two categorical response variables reflecting creativity sources and cultural values

$3 D$

Aha Serendipity

Relationship Risk tolerance Resources

233557

162516136251913

||l|

573424115

Table 5 shows the simplest $2 \times 2$ structure, where all three properties of 3D, Aha! Moment and serendipity were merged into one level of the covariate $(K=1)$, while given fixed level of creativity, it is worthwhile to see how stages of development and cultural values interact with each other.

Table 5 The $2 \times 2$ structure between two categorical response variables reflecting stages of business development and cultural values

\begin{tabular}{l}
\hline Entrepreneur \\
52 \\
Businessperson \\
\hline Risk tolerance Resources \\
3580 \\
17183545 \\
$\|$
\end{tabular}

With these questions in mind, the next section provides some findings from tests performed on the datasets we derived from our primary and secondary data sources.

\section{Empirical results}

The following results were obtained through several separate statistical tests - namely tests on associations of categorical variables for some $\mathrm{X}_{\mathrm{i}} \times \mathrm{Y}_{\mathrm{j}} \times \mathrm{Z}_{\mathrm{k}}$ structures with I and $\mathrm{J}$ varying from 2 to 3 , and $\mathrm{K}$ from 1 to 3 ; together with a log linear model estimation for fitting data with Poisson distribution, based on our data sample, using SAS system. We report only key statistics that helps derive substantial insights gained from the above sample.

\section{$\underline{5.1 \text { A first look at a naiveté of equal likelihood }}$}

Table 4 does not distinguish between stages of development, meaning that it does not matter much whether a firm is in its entrepreneurial phase or is well established. Instead, we focus solely on the three sources of creativity and three cultural values.

Before the test, we expected an equally likely outcome for each value of each dimension of Table 4 , and now see that the marginal frequencies for the row and column vectors now become: $n_{i^{+}}=(23,35,57)$ and $n_{+j}=(57,34,24)$,

respectively. ${ }^{2}$ The first test is for these two vectors of values against the hypothetical guess of equally likely values employing the standard Pearson chi-square test statistic (Agresti, 2002; Azen and Walker 2011). The outcome shows for two degrees of freedom $(\mathrm{df}=3-1=2), \chi^{2}=15.53$, leading us to reject our previous 'naiveté' on probabilities of each of 3R or sources of creativity, since the statistic is much larger than critical value at $\mathrm{df}=2$ being 5.99 . 
In fact, our previous expectation held, since although there is no support for such equal likelihood in the Table 3, at the first fixed level of covariate 'stage of development' in Table 2, we could observe at least the column vector of marginal frequencies $(19,17,16)$ that looks quite promising candidate for our $(1 / 3,1 / 3,1 / 3)$ hypothesis. And we now have $\chi^{2}=0.27$ and could not reject our seemingly-naïve null hypothesis.

\subsection{Independence versus homogeneous/partial associations among variables}

For the $3 \times 3 \times 2$ table, with covariate $\mathrm{K}$ representing stages of development, we now perform a test of homogenous association, controlling for each value of $\mathrm{K}$ ( $\mathrm{E}$ or $\mathrm{B}$ ), and we obtain the following interesting results.

63115

Table 6 Summary of key statistic values for test on hypothesis of independence between 3R and creativity sources $(\mathrm{C} / \mathrm{A} / \mathrm{S})$

Partial table of $3 R \times C / A / S$, controlling for

$\mathrm{K}=\mathrm{E} \mathrm{K}=\mathrm{B}$

Stats.

Likelihood ratio Size $=52$ Likelihood ratio Size $=63$

$d f \chi^{2} 41.06$

412.64

p-value

0.90110 .0132

Note: The $\chi^{2}$ critical value at $\mathrm{df}=4, \alpha=5 \%$ is 9.49 .

For homogeneous association hypothesis, our examination reports the CMH statistic $\chi^{2}=7.01$ (with $\mathrm{p}=0.14$ ). We could not reject the null hypothesis that basically the two partial tables for control of stage (entrepreneurship and business) show no evidence for significantly different structures. But, the test statistic for each of the two-way tables provided in Table 6 shows a significant difference for our control of stage. Specifically for 'entrepreneurship period' (E) the two dimensions of 3R and creativity sources have shown statistical independence. But that is not the case with better established enterprises (B) where we see very clear evidence of conditional association between for the partial table of joint frequencies between relation/risk/resources and 3D/aha/serendipity, because our likelihood ratio $\chi^{2}=12.64$ is larger than the critical value 9.49 with 4 degrees of freedom).

Table 3, with the $2 \times 2 \times \mathrm{K}$ structure, enables us to compute the Breslow-Day chi-square test statistic for homogeneous association null hypothesis. Breslow-Day statistic is a chi-square and for our test it has $\mathrm{df}=(2-1)(2-$ $1)(3-1)=2$. Using, data provided in Table 2 we get $\chi^{2}=1.09$, much smaller than 5.99 , which leaves p-val. equal to 0.58 . We thus cannot reject the hypothesis of homogeneous association across values of our 'creativity covariate' at any conventional level of significance. In other words, in different properties of creativity, the conditional associations between risk/resources and phases of business are not significantly different, following results summarised in Table 7, using mainly the likelihood ratio test statistic ( $\mathrm{G}^{2}$ chi-square) for 1 degree of freedom; that is a corresponding critical value for $\chi^{2}=3.84$ at the conventional $5 \%$ significance level. 
This is an author-produced, peer-reviewed version of this article. The final, definitive version of this document can be found online at International Journal of Transitions and Innovation Systems, published by Inderscience. Copyright restrictions may apply. doi: 10.1504/IJTIS.2013.056595

Table 7 Summary of key statistic values for test on hypothesis of independence between 2R and phase of development (E/B)

Partial table of 2-R $\times E / B$, controlling for G2 p-val. Size

3D 0.170 .6857 Aha! Moment 0.120 .7234 Serendipity 1.090 .3024

Note: Note: $\chi^{2}$ critical value at $\mathrm{df}=1 ; \alpha=5 \%$ is 3.84

Outcome

Not rejected Not rejected Not rejected

We could see also that for the overall sample, provided in Table 5 with dimensions $2 \times 2-$ where we do not split the dataset into different fixed levels of covariate following creativity value as in Table 7 , the test result would most likely follow the same conclusion. In fact, we obtain a $\mathrm{G}^{2}$ of 0.23 (sample size=115; $\mathrm{df}=1, \alpha=5 \%$ ) which could not reject the starting hypothesis of statistical independence among two variables describing values of cultures and phase of business development. This confirmation of independence with a 95\% confidence between business phase and cultural values would mean that joint probabilities of the Table 3 can be computed using the marginal probabilities following the rule of: $\mathrm{p}_{\mathrm{ij}}=\mathrm{p}_{\mathrm{i}+\mathrm{p}+\mathrm{j}}=\left(\mathrm{n}_{\mathrm{i}+} / \mathrm{n}_{++}\right)\left(\mathrm{n}_{+j} / \mathrm{n}_{++}\right)$.

\subsection{Analysis of log-linear models for three-way contingency tables}

The three parsimonious log-linear specifications that we like fitting our dataset to are equations (1), (2), and (3).

In fact, equations from (2) to (4) represent what are defined as conditional associations on $\mathrm{X}$, Y and Z, respectively, while (2) is a specification for homogeneous association. Toward the end, we compare these to the saturated loglinear model for appraising goodness-of-fit for our datasets. ${ }^{3}$ 
Table 8 Summary of key test statistics for goodness of fit for test on log-linear model independence vs. association among variables

Model

Saturated model Homogeneous association (1)

Conditional association on 'stages'

Conditional association on 'cultures'

Conditional association on 'creativity'

Complete independence (5)

Deviance No. of params

0.0018

5.461413 .6910

13.72125 .8312

22.046

$d f G 2$

$0 \mathrm{~N} / \mathrm{A}(*) 4\left(^{*}\right) 5.4688 .23$

68.26

$60.83128 .22(*)$

p-Val.

N/A 0.2430 .084

0.0160 .6600 .013

Notes: $\left(^{*}\right)$ N/A: not applicable; df: $(3-1)(3-1)(2-1)=4$; deviance change test statistic: $8.22=(22.04-5.83)$.

In Table 8, no statistics on three other models on joint independence are reported. However, we do perform estimations to observe goodness of fit for our dataset, and conclude that the above six estimations are sufficient to reach some meaningful insights for the investigation at hand.

The saturated model does not show better fit to data than our (1) due to insignificant $\mathrm{G}^{2}$ statistic (deviance change) of $5.46(\mathrm{df}=4 ; \mathrm{p}=0.24)$, so that the null hypothesis of $\mathrm{H}_{0}: \lambda_{\mathrm{ijk}} \mathrm{XYZ}=0$ is not rejected, thus a third-way interaction term should be eliminated from our selection of model for explanation. Similarly, the 'complete independence' model is also not the best fitting due to its deviance increase that reduces model fit to the (4) is significant at $5 \%$ level $\left(G^{2}=8.22 ; \mathrm{df}=6 ; \mathrm{p}=0.013\right)$. 
This is an author-produced, peer-reviewed version of this article. The final, definitive version of this document can be found online at International Journal of Transitions and Innovation Systems, published by Inderscience. Copyright restrictions may apply. doi: 10.1504/IJTIS.2013.056595

We now arrive at the fitting one, i.e., equation (4) - which implies conditional association among variables, controlling for creativity sources as the most parsimonious specification with complete estimates being provided in Table A1 (see Appendix). One two-way term is significant at $1 \%$ level, which is the $\mathrm{E} \times 3 \mathrm{D}$. This is quite close to what we observe from the homogeneous association specification fitting (2), provided in Table A2.

\section{Final Remarks and Implications for Research}

Our data analysis suggests some insights from the study of interactions between three categorical variables - in nature - as well as some thinking about further study of related management issues. From the above transformation of principles of creativity and culture theories into specific data, the use of contingency tables of joint frequencies enabled us to quantify qualitative assessment as count data, which are possible for an empirical investigation.

From the $3 \times 3 \times \mathrm{K}$ consideration, we conclude that organisational growth stage matters (i.e., entrepreneurs and well established phases of business development). In the former, statistical independence is not rejected leading us to explain the relationship between the choice of creativity source and that of cultural values as independent, however with the latter, two-way association is the case. In other words, for an entrepreneur, cultural values do not help define type of creativity. Given such independence, corporate managers may be able to determine the quality of entrepreneurial elements and ability of being creative of a team from measures of a sample, not from the entire staff. In light of this, the corporations could explore what institutional and individual elements should be improved in order to facilitate creativity.

However, when we reorganise the dataset following the $2 \times 2 \times \mathrm{K}$ structure, collapsing 'relationship' into one of the available resources that a business would use, the two-way association is not confirmed. Although in terms of statistical techniques, the simpler structure is preferable, and in most cases is more useful for our understanding, it is not always the best way explain what matters. This reflects the logic of a reality that researchers in both disciplines of creativity and culture research constantly split up different values in some way when pursuing research. One of such example is Hofstede has expanded his dimensions of cultural values from 4 in his 1980 work to 5 in 1991 and to 6 in 2010 (http://geert-hofstede.com/national-culture.html). Still we expect that simpler structures may help since p-value reported in Table 7 vary quite large, and with other sets of data we may reach different conclusions.

The attempt to fit dataset to different log-linear models also allows useful insight. Given a fairly modest dataset (size $=115$ ), it is good enough to decisively select an equation (4) to be the best fitted one. For this model - actually the 'simpler' one (more parsimonious) - fits the data as well as the homogeneous association equation (1). This result rejects the overall statistical independence among three dimensions of our consideration, namely sources of creativity, set of cultural values and phases of business development. In addition, we do capture at least one two-way association term $(\mathrm{E} \times 3 \mathrm{D})$ - whose coefficient is verified by a Wald statistic at $1 \%$ significance level - that helps explain well the distribution of our three-way contingency table. Now that we know at least in the entrepreneurship phase the creative disciplines would help explain the distribution of our data sample, the fact that shows the importance of the 3D aspect of creativity as described in Napier and Nilsson (2008). In fact, the homogeneous association estimation also offers the same conclusion as in Table A2.

We also learn from the above results that the most significant category among all creativity methods employed in Vietnamese enterprises has been the observation of 'creative disciplines' in the 'entrepreneurial phase'. In general, those creative disciplines have played an important role in explaining the structure of data sample, for businesses in both stages of development. In other words, when Vietnamese enterprises pursue creativity - i.e., a new product or new solution - they should employ the 3D creativity model. Last, the template of our model and analysis may also suggest that these structures could be used as an empirical strategy for comparing different datasets specific to different localities or times, such as in other East Asian emerging market economies, such as China, Indonesia, India, or South Korea. 
This is an author-produced, peer-reviewed version of this article. The final, definitive version of this document can be found online at International Journal of Transitions and Innovation Systems, published by Inderscience. Copyright restrictions may apply. doi: 10.1504/IJTIS.2013.056595

\section{References}

Agresti, A. (2002) Categorical Data Analysis, John Wiley \& Sons, New Jersey.

Amabile, T.M. (1996) Creativity in Context, Westview, Boulder.

Amabile, T.M. and Conti, R. (1999) 'Changes in the work environment for creativity during downsizing', Academy of Management Journal, Vol. 42, No. 6, pp.630-640.

Azen, R. and Walker, C.M. (2011) Categorical Data Analysis for the Behavioral and Social Sciences, Routledge, New York.

Barron, F. (1963) 'Needs for order and disorder', in Taylor, C.W. and Bar-ron, F. (Eds.): Scientific Creativity: Its Recognition and Development, John Wiley \& Sons, New York.

DeGraff, J. and Lawrence, K.A. (2002) Creativity at Work: Developing the Right Practices to Make Innovation Happen, Wiley, New York.

Florida, R. (2002) 'The economic geography of talent', Annals of the Association of American Geographers, Vol. 92, No. 4, pp.743-755.

Florida, R. (2005) Cities and the Creative Class, Routledge, London. Glaveanu, V.P. (2010) 'Creativity as cultural participation’, Journal for the Theory of Social Behaviour, Vol. 44, No. 1, pp.48-67.

Greiner, L.E. (1994) 'Evolution and revolution as organization grow', in Mainiero, L. and Tromley, C. (Eds.): Developing Managerial Skills in Organizational Behavior: Exercises, Cases, and Readings, 2nd ed., pp.322-320, Prentice Hall, Englewood Cliffs, NJ.

Hofstede, G. (1984) Culture’s Consequences: International Differences in Work-Related Values, 2nd ed., SAGE, Beverly Hills.

John-Steiner, V. (1997) Notebooks of the Mind: Explorations of Thinking, Oxford University Press, USA.

Kao, J. (2007) Innovation Nation: How America Is Losing Its Innovation Edge, Why It Matters, and What We Can Do to Get It Back, Free Press, New York.

Klein, R.D. (1982) 'An inquiry into the factors related to creativity’, The Elementary School Journal, Vol. 82, No. 3, pp.256-265.

Kolh, K.S. (2007) Americans Doing Business in Vietnam: Communication Differences, COM 9656: International Business Communication.

Kronfeldner, E.M. (2009) 'Creativity naturalized’, The Philosophical Quarterly, Vol. 59, No. 237, pp.577-592.

Minkov, M. (2007) What Makes us Different and Similar: A New Interpretation of the World Values Survey and other Cross-cultural Data, Klasika y Stil, Sofia, Bulgaria.

Napier, N.K. (2010) Insight: Encouraging Aha! Moments for Organizational Success, Praeger, Westport, CT.

Napier, N.K. and Nilsson, M. (2008) The Creative Discipline: Mastering the Art and Science of Innovation, Praeger, Westport.

Napier, N.K. and Thomas, D.C. (2004) Managing Relationships in Transition Economies, Praeger, Westport.

Napier, N.K. and Vuong, Q.H. (2011) 'Getting to the real story: what Vietnamese business people wish foreigners understood about doing business in emerging and transition countries like Vietnam before they start', Int. Journal of Human Resources Development and Management, Vol. 11, Nos. 2/3/4, pp.208-220.

Napier, N.K. and Vuong, Q.H. (2012) 'Serendipity as strategic advantage', in Wilkinson, T. (Ed.): Strategic Management in the 21st Century, Praeger/ABC-Clio, forthcoming, CT. Napier, N.K., Leonard, N.H. and Sendler, Z. (2006) 'Facilitating management and marketing

creativity in global markets', Organizational Dynamics, Vol. 35, No. 3, pp.220-236. Paulus, P.B. and Nijstad, B.A. (2003) Group Creativity: Innovation through Collaboration, Oxford University Press, New York.

Runco, M.A. (2004) ‘Creativity’, Annual Review of Psychology, Vol. 55, No. 1, pp.657-687.

Runco, M.A. and Richards, R. (1997) Eminent Creativity, Everyday Creativity, and Health, Ablex Publishing, Greenwich.

Sternberg, R.J. (1999) 'The theory of successful intelligence’, Review of General Psychology, Vol. 3, No. 4, pp.292316.

Stokes, M.E., Davis, C.S. and Koch, G.G. (2000) Categorical Data Analysis using the SAS® System, SAS Institute, North Carolina.

Unsworth, K.L. (2001) 'Unpacking creativity’, Academy of Management Review, Vol. 26, No. 2, pp.286-297.

Vuong, Q.H. and Tran, T.D. (2009) 'The cultural dimensions of the Vietnamese private entrepreneurship', The IUP J. of Entrepreneurship Development, Vol. 6, Nos. 3/4, pp.54-78. 
This is an author-produced, peer-reviewed version of this article. The final, definitive version of this document can be found online at International Journal of Transitions and Innovation Systems, published by Inderscience. Copyright restrictions may apply. doi: 10.1504/IJTIS.2013.056595

Vuong, Q.H., Dam, V.N., van Houtte, D. and Tran, T.D. (2011) 'The entrepreneurial facets as precursor to Vietnam's economic renovation in 1986', The IUP J. of Entrepreneurship Development, Vol. 8, No. 4, pp.1-42.

Vuong, Q.H., Tran, T.D. and Nguyen, T.C.H. (2010) ‘M\&A market in Vietnam’s transition economy', Journal of Economic Policy and Research, Vol. 5, No. 1, pp.1-54.

Wallas, G. (1926) The Art of Thought, Harcourt, Brace and Company, New York.

\section{Notes}

. 1 Dataset is available upon direct request to the corresponding author.

. 2 We need to provide one statistic for this since both vectors $\left\{\mathrm{n}_{\mathrm{i}+}\right\}$ and $\left\{\mathrm{n}_{+\mathrm{j}}\right\}$ represent quite similar values of constituting elements, except in different orders.

. 3 The saturated model adds the last term of three-way interaction $\lambda_{\mathrm{ijk}}{ }^{\mathrm{XYZ}}$ to equation (1) for homogeneous association model.

\section{Biographical Notes}

Quan Hoang Vuong is a Senior Research Scientist at Centre Emile Bernheim, Universite Libre de Bruxelles, Belgium. He received the Vietnam National Book Award in 2007 and Vietnam National Journalism Award in 2010. His scholarly works appear in journals such as Economics Studies, IUP Journal of Entrepreneurship Development, Journal of Economic Policy and Research, Int. Journal of Human Resources Development and Management, Int. Journal of Business and Management, Management Research Review, Vietnam Journal of Mathematics, Vietnam Journal of Mathematical Application, VNU Journal of Science; and also as book chapters in edited volumes.

Nancy K. Napier is a Professor of International Business and Strategic Management and Executive Director of Centre for Creativity and Innovation, College of Business and Economics, Boise State University, USA. She has been a widely published author in HRM, international business, cross-cultural management, and recently creativity and innovation. Her scholarly articles appeared in such journals as Journal of Management Studies, Journal of Business Ethics, Human Resource Planning, Journal of International Business Studies, Personnel Psychology, Human Resources Management, and Management International Review. In 2012, she was awarded Honourable Medal of Education for her contribution to Vietnam's educational reforms.

Tri Dung Tran is a Managing Partner at the Hanoi-based DHVP Research \& Consultancy. For ten years now, he has been in the consulting services, serving various institutional customers, ranging from Vietnamese private-sector business firms, government agencies to international donor-funded programmes. He co-authored many articles published by such journals and magazines as Communist Review, Int. Journal of Business and Management, Vietnam Investment Review, and IUP Journal of Entrepreneurship Development. 


\section{Appendix}

\section{A1 Estimation of equation (4)}

Table A1 Estimations for the most parsimonious log linear model using data in Table 2

Parameter df Estimate

S.E. $\chi^{2} 0.40013 .420 .4332 .560 .5263 .300 .4942 .450 .4578 .680 .4922 .540 .5167 .210 .5521 .570 .6160 .680 .911$

2.020 .5880 .310 .6110 .42

p-value

$<0.010 .110 .070 .12<0.010 .11<0.010 .210 .410 .160 .580 .52$

p-value

$<0.010 .210 .090 .10<0.010 .110 .730 .56<0.010 .210 .370 .170 .500 .48$

$\overline{\text { Intercept Phase }-\mathrm{E} 3 \mathrm{R}-\text { relation } 3 \mathrm{R} \text { - risk }} \overline{\text { Creativity }-3 \mathrm{D} \text { Creativity }- \text { aha }}$ Phase $\times$ Creativity $-\mathrm{E} \times 3 \mathrm{D}$ Phase $\times$ Creativity $-\mathrm{E} \times$ Aha $3 \mathrm{R} \times$ Creativity - Relation $\times 3 \mathrm{D} 3 \mathrm{R} \times$ Creativity - Relation $\times$ Aha $3 \mathrm{R} \times$ Creativity - Risk $\times$ 3D $3 \mathrm{R} \times$ Creativity - Risk $\times$ Aha

$11.466^{\mathrm{a}} 10.6931-0.956^{\mathrm{C}} 1-0.77311 .347^{\mathrm{a}} 10.7851-1.386^{\mathrm{a}} 1-0.69310 .5091-1.29610 .32710 .394$

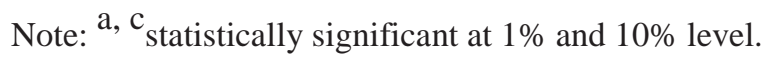

A2 Estimation of equation (2)

Table A2 Estimations for the homogeneous association model using data in Table 2

Parameter df Estimate

S.E. $\chi^{2} 0.40914 .020 .4671 .610 .6382 .850 .5812 .660 .4528 .560 .4862 .520 .5340 .120 .4470 .330 .5207 .370 .560$ 1.570 .6430 .790 .9151 .910 .6090 .450 .6170 .50

$\overline{\text { Intercept Phase }-\mathrm{E} 3 \mathrm{R} \text { - relation } 3 \mathrm{R} \text { - risk }} \overline{\text { Creativity }-3 \mathrm{D} \text { Creativity - aha }}$ Phase $\times 3 \mathrm{R}-\mathrm{E} \times$ Relation Phase $\times$ 3R $-\mathrm{E} \times$ Risk Phase $\times$ Creativity $-\mathrm{E} \times 3 \mathrm{D}$ Phase $\times$ Creativity $-\mathrm{E} \times$ Aha $3 \mathrm{R} \times$ Creativity - Relation $\times 3 \mathrm{D} 3 \mathrm{R} \times$ Creativity - Relation $\times$ Aha $3 \mathrm{R} \times$ Creativity - Risk $\times 3 \mathrm{D} 3 \mathrm{R} \times$ Creativity - Risk $\times$ Aha

1 1.532a $10.5931-1.077^{\mathrm{C}} 1-0.950^{\mathrm{C}} 11.3215^{\mathrm{a}} 10.77210 .18310 .2581-1.412^{\mathrm{a}} 1-0.70210 .5711-1.2651$ 0.41410 .437

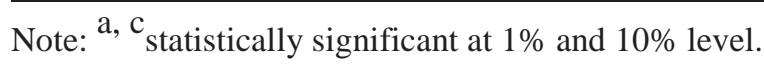

